\title{
Sobre a crítica de Jürgen Habermas ao projeto frankfurtiano: separação epistemológica ou continuidade de uma tradição ${ }^{1}$
}

\section{J ürgen Habermas and the Frankfurtian project: epistemologic separation or continuation of a tradition?}

\author{
Aluísio Ferreira de Lima* \\ Universidade Federal do Ceará - UFC, Sobral, CE, Brasil
}

\begin{abstract}
RESUMO
Nesse ensaio pretendemos apresentar aquilo que entendemos ser o estatuto teórico da Teoria Crítica e, a partir disso, explorar o diálogo que Jürgen Habermas faz com essa tradição. Através da apresentação das proposições de Max Horkheimer, Theodor Adorno e Herbert Marcuse, pretendemos evidencias como Habermas tem assumido o compromisso ético-político pela transformação social e pela emancipação humana que caracteriza o projeto frankfurtiano desde a primeira geração, assim como por meio da crítica aos antigos mestres elabora a ampliação do significado da racionalidade a partir de um novo marco de interpretação, para além da redução à razão instrumental. Finalmente, com essa discussão poderemos assinalar como sua proposta para a Teoria Crítica oferece elementos imprescindíveis para a contrução de uma Psicologia Social Crítica.

Palavras-Chave: Psicologia Social, Teoria Crítica, Escola de Frankfurt, Jürgen Habermas, Ação Comunicativa.
\end{abstract}

\begin{abstract}
In this essay we intend to present what we believe to be the theoretical status of critical theory and explore the dialogue that Jürgen Habermas makes this tradition. Through the presentation of the propositions of Max Horkheimer, Theodor Adorno and Herbert Marcuse, we want evidence as Habermas has taken the ethical and political commitment to social transformation and human emancipation that characterizes the Frankfurtian project since the first generation, as well as through criticism of Old Masters draw the extension of the meaning of rationality from a new framework of interpretation, beyond the reduction of instrumental reason. Finally, we will show how his theory offers essential for the construction of a critical social psychology.
\end{abstract}

Keywords: Social Psychology, Critical Theory, Frankfurt School, Jürgen Habermas, Communicative Action.

Dedicado à Antonio da Costa Ciampa, orientador, mestre e amigo, que mais do que uma direção única a seguir, ensinou-me a beleza de viajar pelos diferentes caminhos. 
Não é nenhuma novidade a fecundidade dos trabalhos desenvolvidos pelos intelectuais do Institut für Sozialforschung, também conhecido como Escola de Frankfurt, para o desenvolvimento da Psicologia Social. B. D. Parrigin (1972), professor da Universidade de Leningrado na extinta União Soviética, na década de 60 do século passado, não exitou em assinalar que os estudos realizados pelos representantes frankfurtianos foram decisivos para desenvolver as bases da Psicologia Social de orientação materialista-dialética. Do mesmo modo, Silvia T. M. Lane (1984), no livro Psicologia Social: Homem em movimento, em meados da década de 80 no Brasil, já assinalava a proficuidade dos trabalhos desenvolvidos por $\mathrm{M}$. Horkheimer e T. W. Adorno para o desenvolvimento de uma Psicologia Social Crítica. Além disso, autores contemporâneos cujas análises direcionadas à razão instrumental e à tecnologia, seguindo o projeto de pesquisas críticas idealizado por Max por Horkheimer e Theodor W. Adorno, mostraram como diversos fragmentos presentes na sociedade denunciam que o projeto kantiano do esclarecimento (Aufklarung) e hegeliano de vida ética (Sittlichkeit) ainda não se realizaram, reforçando o diagnóstico de que a modernidade ainda é um projeto inacabado (HABERMAS, 1992).

As proposições elaboradas pelos teóricos da primeira geração frankfurtiana, inclusive, serviram de base para que autores, como Jürgen Habermas, continuassem os trabalhos iniciados na Escola de Frankfurt e desenvolvessem a compreensão de que as patologias da modernidade são fruto da colonização do mundo da vida pela lógica instrumental/sistêmica. No que se refere a Habermas, suas ideias sobre a racionalidade comunicativa, desenvolvidas a partir do diálogo com os antigos mestres e atuais teóricos das ciências humanas, direcionam seu olhar para o contexto social, do qual procura explorar as condições da instituição de um sistema democrático e pela extensão do universalismo moral que, em outro momento, Kant e Hegel assinalaram levando a razão ao seu extremo mais absoluto (HABERMAS, 1981/1987a; HABERMAS, 1981/1987b).

De fato, em seus últimos trabalhos, de Habermas têm se voltado principalmente para o diagnóstico que caracteriza o século XXI como a era da Globalização, sendo referência para diversas disciplinas das Ciências Humanas e objeto de crítica para diversos intelectuais. No Brasil a apropriação das ideias de Habermas tem sido frequentemente apropriadas para embasar diversas discussões teóricas e pesquisas, tanto por parte de estudantes e docentes das diferentes áreas das ciências humanas e sociais, como também por estudiosos da teoria política (SOUZA, 1997), semiótica e comunicação (PRADO, 1996a; PRADO, 1996b), epistemologia da ciência (SANTOS, 2007), estudos de identidade (CIAMPA, 1987; LIMA, 2008; LIMA, 2009), teoria do direito (OLIVEIRA, 2004), entre outras. 
Reconhecendo a importância desse autor para a Psicologia Social brasileira, a complexidade das ideias desse autor e, principalmente, a impossibilidade de acessar sua obra de imediato e encontrar os nexos que conferem o título de herdeiro da Escola de Frankfurt (devido a irregularidade e descontiuidade com que as obras de Habermas tem sido traduzidas para o português), pretendemos, nas breves páginas deste ensaio, assinalar como Habermas assume o compromisso éticopolítico pela transformação social e pela emancipação humana que caracteriza o projeto frankfurtiano desde a primeira geração. Para cumprir tamanha tarefa faremos um percurso que será iniciado com a apresentação do estatuto teórico da Teoria Crítica e a partir dele iremos inserir o diálogo que Jürgen Habermas faz com essa tradição. Com isso deizaremos em evidência as principais ideias que inauguram a Teoria Crítica e possibilitam sua utilização na leitura dos problemas sociais e como Habermas organiza sua proposta teóricoepistemológica frente a herança frankfurtiana.

\section{O estatuto teórico-epistemológico da Teoria Crítica}

Costumeiramente escreve-se que Teoria Crítica geralmente é o nome dado ao conjunto teórico-metodológico filosófico de um grupo formado por intelectuais marxistas não-ortodoxos que estavam ligados ao Instituto de Pesquisas Sociais filiado a Universidade de Frankfurt na década de 20 do século passado. A história empírica do Instituto é bastante conhecida e pode ser melhor aprofundada nos trabalhos de Freitag (2004); Bronner (1997); Wiggershaus (2002). Após a Semana Marxista de Trabalho, realizada em 1922, reunindo um grupo de intelectuais eminentes concentrados em torno da temática Marxismo e Filosofia, que reuniu Lukács, Wittfogel, Pollock, Horkheimer, Massing e outros. Karl Korsh (associado tradicionalmente a Antonio Gramsci e a Georg Luckács foram considerados como os precursores do marxismo ocidental") e Felix Weil, idealizadores e organizadores da semana, decidem fundar um "instituto para estudos marxistas". No ano seguinte, em fevereiro, o "Instituto de Pesquisas Sociais" é fundado em Frankfurt. Os principais expoentes desse instituto foram Max Horkheimer, Theodor Adorno, Herbert Marcuse e Walter Benjamin. Após a ascensão de Hitler ao poder, janeiro de 1933, o Instituto é decretado como ilegal, o que faz com que as atividades sejam deslocadas para as cidades de Genebra (1933), Paris (1933 a 1936) e Londres (1933 a 1934). Após esse período, Adorno e Horkheimer fixam as atividades do Instituto em Nova York (1934) e Los Angeles (1941), retornando para Frankfurt após 1950.

Entretanto, mesmo que os diferentes autores tenham mantido um esqueleto comum frente aos temas estudados e que algumas produções sejam conjuntas, os mesmos não deixaram nenhum corpus teórico comum ou integrado. O segundo ponto a ser 
considerado é que se o nome de Habermas pode ser vinculado à Escola de Frankfurt, sua filiação teórica, embora corresponda à "segunda geração", apenas refere-se à produção inicial do Instituto, ou seja, aquela compreendida entre os anos de 1930-1940, momento em que os projetos estavam voltados para a análise das relações sociais e as possibilidades de transformação da realidade. Isso se torna visível ao observarmos que os demais temas trabalhados entre os anos de 1940 e 1970 pelos fundadores do Instituto serão rejeitados por Habermas. Bárbara Freitag (2004, p. 84) explica que, após os escritos da década de 40 do século passado esse teórico busca desenvolver o projeto de uma razão comunicativa para combater a razão instrumental, o marxismo e a psicanálise. Como veremos adiante, uma postura que estaria relacionada ao fato de Habermas acreditar que as propostas desenvolvidas a partir da Dialética do Esclarecimento até a Teoria Estética, teriam levado ao desgaste a filosofia da consciência subjetiva.

Nesse sentido, Teoria Crítica é mais do que um nome dado para o conjunto de intelectuais que trabalharam em uma insituição de pesquisa. Teoria Crítica refere-se a um campo teórico-epistemológico muito mais amplo, mais especificamente a um campo teórico que mantém uma forte relação com o marxismo, no sentido que the foi atribuído por Max Horkheimer em 1937 no ensaio Teoria Tradicional e Teoria Crítica (HORKHEIMER, 1937/1980). De acordo com Horkheimer, a Teoria Crítica deve ser pensada como uma produção de conhecimento que não apenas descreve a sociedade, mas que pretende compreendê-la à luz de uma emancipação ao mesmo tempo possível e bloqueada pelos mecanismos de dominação presente.

Nesse texto Horkheimer reforça o compromisso da Teoria Crítica com a grande problemática da Modernidade: a saída da menoridade que o homem se colocou ao abrir mão de servir-se de seu próprio entendimento, tal como postulado por Immanuel Kant (1784/2004). Menoridade que fica explícita como ainda não superada no período em que vivemos, no qual o mercado oferece diversas alternativas para que os indivíduos não tenham que pensar por si mesmos, servindo como exemplo a imensa quantidade de livros (de autoajuda) que pensam por nós mesmos, diretores espirituais que têm por nós consciência moral, médicos que decidem a dieta, analistas simbólicos que direcionam nossas carreiras e sentimentos etc., ao ponto que não precisamos utilizar nossa própria racionalidade. Como ensina Kant, uma menoridade reforçada por uma racionalidade indolente cuja lógica segue a premissa de que "não me é forçoso pensar, quando posso simplesmente pagar; outros empreenderão por mim essa tarefa aborrecida" (1784/2004, p. 12). Momento histórico em que o próprio conhecimento e a técnica que deveriam libertar os indivíduos são invertidos em algemas que impedem a emancipação e que os próprios cientistas estão atrelados aos aparelhos ideológicos 
do Estado, em que "suas realizações constituem um momento de autopreservação e da reprodução contínua do existente, independentemente daquilo que imaginam a respeito disso" (HORKHEI MER, 1937/1980, p. 123).

Horkheimer escreve que a atividade cognitiva que guia o conhecimento pode seguir uma lógica completamente diferente do seu objeto de estudo. Seguindo esse argumento, continua dizendo que não se questiona o significado da teoria, mas o uso de uma teoria desenvolvida "de cima para baixo", "elaborada sem o contato direto com os problemas de uma ciência empírica particular" (HORKHEIMER, 1937/1980, p. 119), em que a produção teórica transforma-se em produto. E a partir desse "diagnóstico" Horkheimer defende a tese de que a onipotência da esfera capitalista estaria transformando todas as relações sociais e individuais em "um fim em si mesmas" e que a missão da Teoria Crítica seria superar essa relação "para uma concepção que elimine a parcialidade que resulta necessariamente do fato de retirar os processos parciais da totalidade da práxis social" (HORKHEIMER, 1937/1980, p. 124). Para tanto, torna-se necessária uma mudança estrutural na concepção de atividade científica que leve a admitir que:

\begin{abstract}
A maneira pela qual as partes são separadas ou reunidas na observação registradora, o modo pelo qual algumas passam despercebidas e outras são destacadas, é igualmente resultado do moderno modo de produção, assim como a percepção de um homem de uma tribo qualquer de caçadores ou pescadores primitivos é o resultado das suas condições concretas de existência, e portanto, indubitavelmente também do objeto. (...) O que o membro da sociedade capitalista vê diariamente à sua volta: conglomerados habitacionais, fábricas, algodão, gado de corte, seres humanos, e não só estes objetos como também os movimentos, nos quais são percebidos, de trens subterrâneos, elevadores, automóveis, aviões etc., tem este mundo sensível os traços do trabalho consciente em si; não é mais possível distinguir entre o que pertence a natureza inconsciente e o que pertence a práxis social. Mesmo quando se trata da experiência com objetos naturais como tal, sua neutralidade é determinada pelo contraste com o mundo social, e nesta medida dele depende (HORKHEIMER, 1937/1980, p. 126).
\end{abstract}

O teórico, por sua vez, deve estar atento ao fato de que sua função não é o de prestador de serviço da realidade administrada, mas sim, um dos responsáveis por sua transformação. Sua orientação ética deve comprometer-se com a liberdade humana e com as lutas políticas das classes oprimidas. E essa orientação para a emancipação, como explicita Theodor Adorno (1959/2006, p. 169), deve ser caracterizada por uma postura crítica frente ao 
conhecimento produzido e à própria realidade social que esse conhecimento pretende apreender. Caso contrário, estaríamos aplicando a palavra emancipação num sentido meramente retórico, tal como ocorre com outras palavras que são utilizadas cotidianamente por serem politicamente corretas. A dificuldade, sem dúvida, é eminente e persistente, afinal, ainda hoje vivemos uma organização social que prega a liberdade e contraditoriamente promove uma seminformação (ADORNO, 1959/2006). A autonomia se inverte na liberdade em escolher entre as ofertas de mercado, e, como assinala Adorno:

(...) enquanto isto ocorre, a sociedade forma as pessoas mediante inúmeros canais e instâncias mediadoras, de um modo tal que tudo absorvem e aceitam nos termos desta configuração heterônoma que se desviou de si mesma em sua consciência (1959/2006, p. 181).

O objetivo do pensamento crítico fica claro nessa síntese: a atividade do pesquisador crítico que esteja comprometido com a emancipação humana, que tenha como meta a transformação do todo social, não pode servir-se do trabalho teórico conforme é esperado pela ordem social vigente. Todo aquele que se proponha a desenvolver um pensamento crítico deve dispensar "o caráter pragmático que advém do pensamento tradicional como um trabalho socialmente útil", e lançar sobre este o questionamento acerca de para quem determinado conhecimento está sendo produzido, uma vez que "um pensamento que não reconheça esses limites parece perder suas bases" (HORKHEIMER, 1937/1980, p. 131). O teórico crítico deve orientar-se por regras de registro e ordenamento dos dados que se diferenciam (o que evidentemente não é pouca coisa) das teorias tradicionais e abrir mão das predições, uma vez que "a predição não depende meramente do aperfeiçoamento dos métodos e da argúcia (...), mas depende igualmente da evolução de seu objeto: das transformações estruturais da própria sociedade" (HORKHEIMER, 1933/2006, p. 94).

A Teoria Crítica, de acordo com Horkheimer, aspira algo mais que constatar as misérias do presente. A dinâmica que conduz a superação da teoria tradicional está assinalada, sobretudo, na postura que promove o interesse em suprimir as injustiças sociais.

A teoria crítica não tem, apesar de toda a sua profunda compreensão dos passos isolados e da conformidade de seus elementos com as teorias tradicionais mais avançadas, nenhuma instância específica para si, a não ser os interesses ligados à própria teoria crítica de suprimir a dominação de classe (HORKHEIMER, 1937/1980, p. 154). 
Os limites da reflexão crítica, tanto ao produzir como ao afirmar os conteúdos de futuro, cooperam na idealização de uma teoria que, precisamente por conta da ausência de formulações conclusivas, ampliam as possibilidades de análise da modernidade para além do contexto de seu nascimento. A atitude crítica resiste a aceitar como superados os ideais modernos e questiona em que medida a determinação dos objetivos da tradição têm se revelado como vazios de conteúdo. O fracasso dos desejos modernos, materializados na instrumentalização das relações, não corresponderia ao fracasso de seu projeto porque, como tal, continua inspirado no inconformismo com as situações do presente que nem cumprem nem inspiram a cumprir a emancipação humana. A clareza de que quando se antecipa o futuro não estamos tratando com algo material (expressado historicamente como progresso técnico) permite à Teoria Crítica defender-se da acusação de que sua confiança na emancipação poderia coincidir com a entrega acrítica frente as dificuldades do pensar para além da sociedade atual, que foi identificada como "racionalidade formal" da cientificidade por Max Weber.

\section{A crítica aos limites da razão a partir da dialética do esclarecimento}

De acordo com Herbert Marcuse, o processo de racionalização descrito por Weber não teria implantado a racionalidade propriamente dita, mas sim, "uma forma determinada de dominação política oculta". Como explica Jessé Souza (1997), em Weber existe uma diferença entre racionalismo e racionalidade: 1) racionalidade referese ao imperativo de qualquer existência humana de "tornar-se uma personalidade na medida em que a corrente de decisões última que dá, em última instância, o sentido da individualidade de uma vida, passa a ser conscientemente executada e mantida" (SOUZA, 1997, p. 69); 2) racionalismo, por sua vez, "significa a forma, culturalmente singular, como uma civilização específica, e por extensão também os indivíduos que constituem sua maneira de pensar e agir a partir desses modelos culturais, interpretam o mundo" (SOUZA, 2006, p. 8). Em outras palavras, a "ação racional referente a fins" derivada deste tipo de racionalidade "racionalista" nada mais é do que "exercício de controle". Marcuse, inclusive, perto das considerações finais do ensaio acerca dos conceitos de industrialização e capitalismo na obra de Weber vai escrever que:

(...) a análise do capitalismo de Max Weber não foi suficientemente neutra no que se refere aos valores, na medida em que introduziu os valores específicos do capitalismo nas definições "puras" da racionalidade formal. Assim se desenvolveu a contradição entre racionalidade formal e material, cujo reverso é a neutralidade da razão técnica em face de todos os valores materiais exteriores a 
ela. Por sua vez, essa neutralidade possibilitaria a Max Weber aceitar o interesse (reificado) da nação e seu poder político como valores que determinam a razão técnica.

O conceito de razão técnica talvez seja ele próprio ideologia. Não somente sua aplicação mas já a técnica ela mesma é dominação (sobre a natureza e sobre os homens), dominação metódica, científica, calculada e calculista. Determinados fins não são impostos apenas "posteriormente" e exteriormente à técnica - mas eles participam da própria construção do aparelho técnico; a técnica é sempre um projeto sócio-histórico; nela encontra-se projetado o que uma sociedade e os interesses nela dominantes pretendem fazer com o homem e com as coisas. Uma tal finalidade da dominação é "material", e nesta medida pertence à própria forma da razão técnica (MARCUSE, 1965/1998, p. 132).

Essa análise da racionalidade técnica-instrumental realizada por Marcuse, explorada por Habermas no trabalho Técnica e Ciência como Ideologia (1968/2001a), mostrar-se-á parecida com a realizada por Horkheimer e Adorno na Dialética do Esclarecimento (1969/1985).

Nessa obra Horkheimer e Adorno narram a trajetória da razão que culminaria na "autodestruição do conhecimento". Os autores defendem a tese de que a razão que era concebida inicialmente como elemento central para a emancipação humana e libertaria os homens da natureza externa tornando-os senhores de si e do mundo acabou se convertendo em seu contrário, ou seja, em elemento da própria dominação. Isto posto, seguem dizendo que se o programa do esclarecimento era o desencantamento do mundo, tal como propunha Kant, dissolvendo os mitos e substituindo a imaginação pelo saber (HORKHEI MER; ADORNO, 1969/1985, p. 19), na sociedade capitalista o esclarecimento sofreria uma regressão à ideologia e se esgotaria "na idolatria daquilo que existe e do poder pelo qual a técnica é controlada" (HORKHEIMER; ADORNO, 1969/1985, p. 16), uma falsa clareza que passa a imperar e uma naturalização que se torna regra para o progresso social.

O aumento da produtividade econômica, que por um lado produz as condições para um mundo mais justo, confere por outro lado ao aparelho técnico e aos grupos sociais que o controlam uma superioridade imensa sobre o resto da população. O indivíduo se vê completamente anulado em face dos poderes econômicos. Ao mesmo tempo, estes elevam o poder da sociedade sobre a natureza a um nível jamais imaginado. Desaparecendo diante do aparelho a que serve, o indivíduo se vê, ao mesmo tempo, melhor do que nunca provido por ele. Numa situação injusta, a impotência e a dirigibilidade da massa aumentam com a quantidade de bens a ela destinados. A elevação do padrão de vida das classes inferiores, materialmente considerável e socialmente lastimável, reflete-se na difusão hipócrita do espírito. Sua verdadeira aspiração é a negação da reificação. Mas ele 
necessariamente se esvai quando se vê concretizado em um bem cultural e distribuído para fins de consumo. A enxurrada de informações precisas e diversões assépticas desperta e idiotiza as pessoas ao mesmo tempo (HORKHEIMER; ADORNO, 1969/1985, p. 14-15).

Isso faz com que o aumento do esclarecimento converta-se em um novo aprisionamento. Na medida em que a razão desenvolve-se de modo unilateral - privilegiando apenas a dimensão instrumental em detrimento da dimensão emancipadora - , desvia-se de seu objetivo emancipatório original, desembocando em uma "calamidade triunfal": "o controle totalitário da natureza e a dominação incondicional dos homens" (FREITAG, 2004, p. 34-35). Sinteticamente esse fenômeno pode ser apresentado em duas teses, que são trabalhadas a partir das narrativas épicas de Homero contidas na Odisséia: “o mito já é esclarecimento e o esclarecimento acaba por se converter em mitologia" (HORKHEIMER; ADORNO, 1969/1985, p. 15).

O episódio do Ciclope e o das Sereias presentes na Odisséia servirão para a exemplificação das teses defendidas na Dialética do Esclarecimento. No episódio do Ciclope os autores trabalham com a necessidade da nomeação do indivíduo para sua existência. Seguindo essa lógica de argumentação, mostram como Ulisses, velando-se de sua racionalidade instrumental, faz uso do espaço vazio entre as palavras e coisas para montar sua armadilha e derrotar o Ciclope. O preço para tal façanha é, por sua vez, a negação de si mesmo. Lembremos que, no episódio do Ciclope, Homero descreve um ser que desrespeita todas as regras de hospitalidade, pervertendo as trocas de presente, sendo um portador da guerra e morte. E que Ulisses, ao ser capturado com seus companheiros mostra-se capaz de entender a lógica da barbárie e interagir com a morte, fato evidenciado quando abre mão de seu nome e autodenomina-se como "Ninguém".

Como "Ninguém" oferece ao Ciclope uma porção de seu melhor vinho, como presente das terras desenvolvidas. O Ciclope, por sua vez, em agradecimento pelo presente decide devorar Ulisses por último, não contando que seria seduzido pelo prazer do vinho se embriagaria e cairia no sono. A partir dessa artimanha o herói engendra sua investida contra o monstro furando o único olho com um tronco previamente apontado pelos seus companheiros de viagem. O Ciclope, que acorda com o ferimento, fica sem receber ajuda dos outros monstros, que recebiam a resposta de que "ninguém" havia ferido seu olho.

No outro episódio, também analisado por Horkheimer e Adorno, vemos Ulisses desafiando as advertências de Circe sobre o fato de nenhum navegante resistir ao canto das Sereias. Novamente recorrendo à razão instrumental, Ulisses desenvolve uma alternativa 
para escutar o canto e permanecer intacto, sem lançar-se ao mar devido à sedução das Sereias. A artimanha dessa vez é utilizar-se da ajuda de seus companheiros para ser amarrado por laços estreitos e fortes ao mastro de seu navio. Não podendo se mexer de nenhum modo e acompanhado dos marujos, que estavam protegidos do canto por terem as orelhas tapadas com cera, deixa-se vivenciar o maravilhoso e perigoso canto. O custo da artimanha utilizada por Ulisses novamente aparece como demasiadamente alto: abrir mão da liberdade para viver o fetiche do canto das Sereias e alienar os outros tripulantes do acesso à melodia.

Ulisses com essa ação, como assinalam Horkheimer e Adorno, se autocondena à impotência e ao aprisionamento para poder gozar do canto, e, concomitantemente a isso, condena seus companheiros, trabalhadores, à ordem do senhor, do chefe, a renunciar o gozo artístico, a ficarem surdos para poderem continuar vivos. Reproduzindo sem parar sua força de trabalho.

\begin{abstract}
O que ele [Ulisses] escuta não tem conseqüências para ele, a única coisa que consegue fazer é encenar com a cabeça que o desatem; mas é tarde demais, os companheiros - que nada escutam - só sabem do perigo da canção, não de sua beleza - e o deixam no mastro para salvar a ele e a si mesmos. Eles reproduzem a vida do opressor juntamente com a própria vida, e aquele não consegue mais escapar a seu papel social (HORKHEIMER; ADORNO, 1969/1985, p. 45).
\end{abstract}

Os autores insistem a partir da ilustração feita com os dois episódios que o preço a ser pago pelo surgimento do indivíduo racional, autônomo, ou, simplesmente, o preço a ser pago para se manter vivo, é nada mais, nada menos, que a própria espontaneidade, a criatividade, o êxtase e gozo. Dito de outro modo, a conservação de si a partir da alienação e renúncia de ser si mesmo. Nos é possível dizer que já em Ulisses podemos observar que um dos problemas para o desenvolvimento da identidade encontra-se em sua própria gênese, que se confunde com a renúncia às próprias vontades (desejos) e com a rigidez resultante dessa renúncia. Assim, o preço que os homens pagam pelo seu poder é a alienação sobre o que exercem poder.

\title{
A apropriação habermasiana do projeto frankfurtiano e sua contribuição à Teoria Crítica
}

Na leitura de Habermas, a partir da proposta dos autores citados o "esclarecimento comporta-se com as coisas como o ditador se comporta com os homens. Este reconhece-os na medida em que pode manipulá-los" (HABERMAS, 1985/2002, p. 24). O épico, por sua vez, conteria os elementos que evidenciam a "proto-história de uma 
subjetividade que se desprende da coerção dos poderes míticos" (HABERMAS, $1985 / 2002$, p. 155) e que inauguraria a Modernidade. O herói Ulisses, com o uso de sua razão, seria o exemplo do primeiro homem que teria conseguido derrotar as divindades da natureza ao custo da abdicação da liberdade subjetiva.

Essa constatação fará com que Habermas afirme que para Horkheimer e Adorno os homens formam sua identidade à medida que aprendem a dominar a natureza exterior ao preço da repressão de sua natureza interior, pois a "dominação sobre uma natureza exterior objetivada e uma natureza interior reprimida é o signo permanente do esclarecimento" (HABERMAS, 1985/2002, p. 158); e chegue à conclusão de que o preço a pagar por tal resultado é um imobilismo da práxis, uma vez que a Teoria Crítica tal como Horkheimer e Adorno a conceberam, "em sua fidelidade ao negativo, precisa negar a sua própria competência para pensar o mundo. Assim sendo, ela chega a um ponto final de sua trajetória, deparando-se com outro beco sem saída" (FREITAG, 2004, p. 84-85).

Para Habermas outra limitação na proposta de seus antigos mestres também será observada na análise da racionalidade instrumental realizada por Herbert Marcuse. Para Habermas seria preciso renunciar ao "talvez" empregado por Marcuse ao referir-se sobre a relação ideológica entre técnica e ciência, pois se razão instrumental e dominação política encontram-se inseparáveis, e seu entrelaçamento não pode ser desvelado de imediato, a racionalização das relações vividas equivaleria à institucionalização de uma dominação de conteúdo político irreconhecível, somente passível de ser verificada nas crises de legitimação. A política em sua essência seria a "manutenção de um sistema que pode permitir-se converter em fundamento da sua legitimação o incremento das forças produtivas associado ao progresso técnico-científico" (HABERMAS, 1968/2001a, p. 47).

Uma leitura entendida como paradoxal: uma vez que ao propor uma "repressão objetivamente supérflua", o que poderia servir como plataforma de uma ação revolucionária converte-se, por conta de seu caráter repressivo, no "desvanecer-se da consciência da população", que preferiria o conforto para sua vida cotidiana ao confronto das condições repressivas. Surgindo assim uma "novidade na história mundial": a racionalidade teria se metamorfoseado de "padrão de crítica para as forças produtivas" em "padrão apologético", em outras palavras, em irracionalidade do poder proveniente "das relações de produção historicamente caducas", não mais questionadas, mas justificadas. A racionalidade teria retrocedido, perdendo seu poder crítico, entrado em falência, e se tornado "mero corretivo dentro do sistema", abrindo espaço para o discurso que se tornou moda em nossos dias: se a sociedade vai mal, é porque está mal "programada". O que Marcuse não teria entendido, de acordo com 
Habermas, é que a técnica nada mais é do que o reflexo do modo como os indivíduos trabalham, o que tornaria inviável a renúncia dessa técnica a partir de uma simples substituição, "enquanto não se modificar a organização da natureza humana e enquanto houvermos de manter a nossa vida por meio do trabalho social e com a ajuda dos meios que substituem o trabalho" (HABERMAS, 1968/2001a, p. 52).

Esse ponto pode ser entendido como o divisor de águas entre a primeira geração frankfurtiana e Jürgen Habermas. A superação desse impasse - que em Horkheimer e Adorno levaria à compreensão de que é impossível uma subversão da sociedade administrada; e em Marcuse apareceria possível apenas quando a ciência e a técnica fossem previamente revolucionadas - no parecer de Habermas passa a ser buscado "não na salvação da razão subjetiva e sim numa razão comunicativa intersubjetiva, aplicada em situações dialógicas nas quais os interlocutores buscam através da argumentação fundada o consenso possível" (FREITAG, 2004, p. 85). Ainda assim, Habermas não deixa de lado o compromisso com a denúncia da opressão proposto pela Teoria Crítica, sendo evidente que, tal como seus mestres de convicção racionalista, compartilha de um fundo de incondicionalidade frente à ideia de uma racionalidade inscrita no destino evolutivo da espécie humana.

\begin{abstract}
O momento ideal da incondicionalidade foi profundamente aceite nos processos do entendimento mútuo, pois as pretensões de validade evidenciam um sentido duplo: enquanto algo universal dispara para lá de um qualquer contexto dado simultaneamente, as pretensões de validade têm forçosamente, aqui e agora, de ser levantadas e aceites. No agir comunicativo orientamo-nos por pretensões de validade que, unicamente, no contexto de nossa linguagem, isto é, de nossa forma de vida, podemos levantar factualmente, enquanto a possibilidade de remição, implicitamente instituída por acréscimo, visa em simultâneo para lá da regionalidade do respectivo contexto. Quem se serve de uma linguagem, quando orientado pela compreensão mútua, está exposto a uma transcendência do interior. Ele tão pouco pode dispor disto, como nomear-se dono da estrutura da linguagem mediante a intencionalidade da palavra proferida. A intersubjetividade linguística excede os sujeitos sem, no entanto, os tornar dependentes. O pensamento pós-metafísico diferencia-se da religião por salvar o sentido absoluto sem recurso a Deus ou algo absoluto [tal como foi entendido como inevitável por Horkheimer] (HABERMAS, 1991/2001b, p. 116).
\end{abstract}

A questão da incondicionalidade, inclusive, aparece com frequência tanto em Habermas como em muitos de seus críticos que recriminam essa postura como um déficit na sua construção teórica frankfurtiana 
(HABERMAS, 1991/2001c). No caso da Teoria da Ação Comunicativa, por exemplo, faltaria um elemento material que salvasse 0 argumento indiscutível do valor da busca pelo entendimento (APEL, 2004; Apel, 1999), que já em Kant, referia-se à faculdade de saber e pensar (KANT, 1798/2006, p. 27). I sso certamente não impediu Habermas de defender enfaticamente a possibilidade de salvar 0 sentido incondicionado para os valores morais - que não seriam afetados pela perda histórica do referencial religioso e da força normativa dos imperativos divinos. Um outro trecho do ensaio em resposta à frase de Horkheimer: Querer salvar um sentido absoluto, sem Deus, é pretensioso, parece marcar essa posição:

\begin{abstract}
O sentido de incondicionalidade não significa o mesmo que um sentido absoluto que oferece consolo. Sob as condições do pensamento pós-metafísico, a filosofia não pode substituir o consolo com o qual a religião empurra para uma nova luz, e ensina a suportar o sofrimento inevitável e a justiça nãoexpiada, as contingências de necessidade, solidão, doença e morte. A filosofia consegue, ainda hoje, explicar bem o ponto de vista moral perante o qual julgamos justo e injusto algo imparcial; dentro dessa medida, a razão comunicativa não se encontra, em caso algum, igualmente distante da moral. Contudo, algo bem diferente consiste em dar uma resposta motivadora à pergunta, com base nos nossos conhecimentos morais, e porque devemos ser, em geral, morais. A respeito disso, seria porventura possível dizer que querer salvar um sentido, sem Deus, é pretensioso. Pois faz parte da dignidade da filosofia insistir intransigentemente no facto de que nenhuma pretensão de verdade pode ter uma existência que não se encontre justificada no fórum que a fundamenta (HABERMAS, 1991/2001b, p. 117).
\end{abstract}

Habermas, como podemos perceber, reafirma em todos os trabalhos produzidos sua confiança acerca da força libertadora da razão. E para que esta questão não apareça apenas como uma afirmação retórica, é preciso lembrar que a meta do estatuto teórico da Teoria Crítica é autodeterminação do humano, que inserido nas condições do capitalismo tardio vive tanto "as conseqüências libertadoras e aliviadoras de uma racionalização comunicativa do mundo da vida, como também os efeitos de uma razão funcionalista alvejada" (HABERMAS, 1998/2001e, p. 198). De acordo com o diagnóstico habermasiano, a secularização da política é somente o reverso da autonomia política dos cidadãos, o que, por outro lado, pressupõe os efeitos da secularização (a perda do peso dos argumentos transcendentais e metafísicos) da organização ética de convivência.

À guisa de conclusão, esperamos que com o exposto tenha sido possível perceber que desde a advertência ao componente de incondicionalidade até o esforço frankfurtiano de esboçar uma Teoria Crítica, é possível notar que a presença simultânea de uma 
consciência da necessidade de sair da menoridade e a busca por uma construção teórica capaz de consolidar um conhecimento promotor da emancipação é compartilhada por todos os teóricos ligados à Teoria Crítica - e que Habermas, mesmo com todas as divergências, é um herdeiro dessa tradição. Acreditamos que tenha ficado explícito o fato de que este último compartilha a aposta de seus antecessores em um projeto de ciência que permita aos indivíduos definirem sua liberdade e promoverem uma sociedade autenticamente racional e livre. Em Habermas vemos persistir o componente radical que nenhum teórico crítico pode renunciar: a ampliação do significado da racionalidade a partir de um novo marco de interpretação, para além da redução à razão instrumental. Com isso é possível afirmar que suas proposições, longe de indicar a possibilidade de incorporação totalitária, oferecem elementos imprescindíveis para a construção de uma Psicologia Social Crítica, que deseja pensar o humano para além de uma dominação inevitável ou ausência de horizonte utópico.

\section{Referências Bibliográficas}

ADORNO, T. W. Educação e Emancipação. Tradução Wolfgang Leo Maar. Rio de Janeiro: Paz e Terra, 2006. 4a Edição. (original publicado em 1959)

APEL, K-O. Fundamentação normativa da "Teoria Crítica": recorrendo à eticidade do mundo da vida? In: MOREIRA, L. (Org.). Com Habermas, Contra Habermas: direito, discurso e democracia. Tradução dos ensaios de Karl-Otto Apel por Claudio Molz. São Paulo: Landy Editora, 2004. p. 23-78.

O desafio da crítica total da razão e o programa de uma teoria filosófica dos tipos de racionalidade. In: Novos Estudos CEBRAP, n. 23, março,1999. p. 14-66.

BRONNER, S. E. Da teoria crítica e seus teóricos. Tradução de Tomás R. Bueno e Cristina Meneguelo. São Paulo: Papirus, 1997.

CIAMPA, A. C. A Estória do Severino e a História da Severina: Um ensaio de Psicologia Social. São Paulo: Brasiliense, 1987.

FREITAG, B. Teoria Crítica: Ontem e hoje. São Paulo: Brasiliense, 2004.

HABERMAS, J. O Discurso Filosófico da Modernidade: Doze Lições. Tradução de Luiz Sérgio Repa e Rodnei Nascimento. São Paulo: Martins Fontes, 2002. (original publicado em 1985)

Técnica e ciência como "I deologia". Tradução de Artur Morão. Lisboa: Edições 70, 2001a. (original publicado em 1968)

Excurso: Transcendência do interior, Transcendência para este mundo. In: ___. Textos e Contextos. Tradução de Sandra Lippert Vieira. Lisboa: Instituto Piaget, 2001c. p. 119-145. (original escrito em 1991)

Para uma frase de Horkheimer: Querer salvar um sentido absoluto, sem Deus, é pretensioso. In: __-_-_. Textos e Contextos. 
Tradução de Sandra Lippert Vieira. Lisboa: Instituto Piaget, 2001b. p. 103-117. (original escrito em 1991)

. Concepções de Modernidade: um olhar retrospectivo sobre duas tradições. In: A constelação Pós-Nacional: Ensaios Políticos. Tradução de Márcio Seligmann-Silva. São Paulo: Littera Mundi, 2001d. p. 167-198. (original publicado em 1998)

Modernidade um projeto inacabado. In: ARANTES, O. B. F.; A $\bar{R} \overline{A N T E S}, P$. E. Um ponto cego no projeto moderno de Jürgen Habermas: Arquitetura e dimensão estética depois das vanguardas. São Paulo: Brasiliense, 1992.

Teoria de la Acción Comunicativa: racionalidad de la acción y racionalización social. Traducción de Manuel Jiménez Redondo. Madrid: Taurus, 1987a. Tomo I. (original publicado em 1981)

Teoria de la Acción Comunicativa: crítica de la razón funcionalista. Traducción de Manuel Jiménez Redondo. Madrid: Taurus, 1987b. Tomo II. (original publicado em 1981)

HORKHEIMER. M. Do problema da Previsão nas Ciências Sociais. In: HORKHEI MER. M. Teoria Crítica: uma documentação. Tradução de Hilde Cohn. São Paulo: Perspectiva, 2006. p.89-94. (original escrito em 1933 e publicado em 1968)

ADORNO, T. W. Dialética do Esclarecimento: Fragmentos Filosóficos. Tradução de Guido Antonio de Almeida. Rio de Janeiro: J orge Zahar Editor, 1985. (original publicado em 1969)

HORKHEI MER, M. Teoria Tradicional e Teoria Crítica. In: BENJ AMIN, W.; HORKHEIMER, M.; ADORNO, T. W.; HABERMAS, J. Textos Escolhidos. Traduções de José Lino Grünnewald [et al.]. São Paulo: Abril Cultural, 1980. (original publicado em 1937).

KANT, I. Antropologia do ponto de vista pragmático. Tradução de Clélia Aparecida Martins. São Paulo: Iluminuras, 2006. (original publicado em 1798).

. Resposta a pergunta: O que é o lluminismo? In: KANT, I. Paz perpétua e outros opúsculos. Lisboa: Edições 70, 2004. (original publicado em 1784).

LANE, S. T. M.; CODO, W. (Orgs.). Psicologia Social: O homem em movimento. São Paulo: Brasiliense, 1984.

LIMA, A. F. Sofrimento de indeterminação e reconhecimento perverso: Um estudo da construção da personagem doente mental a partir do sintagma identidade-metamorfose-emancipação. Tese de Doutorado não publicada. São Paulo: PUC-SP, 2009.

Hermenêutica da Tradição ou Crítica das I deologias? O debate entre Hans-Georg Gadamer e Jürgen Habermas. In: UNOPAR Científica: Ciências Humanas e Educação. Londrina. v. 9, n. 1. mar. 2008. p. 57-65.

MARCUSE, H. Industrialização e Capitalismo na obra de Max Weber. In: MARCUSE, H. Cultura e Sociedade II. Tradução de Wolfgang 
Leo Maar, Isabel Maria Loureiro e Robespierre de Oliveira. São Paulo: Paz e Terra, 1998. p. 113-136. (original publicado em 1965)

OLIVEIRA, M. A. Moral, direito e democracia: o debate Apel versus Habermas no contexo de uma concepção procedimental da filosofia prática. In: MOREIRA, L. (Org.). Com Habermas, contra Habermas: direito, discurso e democracia. São Paulo: Landy Editora, 2004. p. 145-176.

PRADO, J. L. A. Brecha na Comunicação: Habermas, o Outro, Lacan. São Paulo: Hacker/CESPUC, 1996a.

. O pódio da normalidade: Considerações sobre a Teoria da Açã̃o Comunicativa e a Psicologia Social. In, Psicologia \& Sociedade, v. 8, n. 1, p. 144-173, jan/jun, 1996b.

SANTOS, B. S. A Crítica da Razão I ndolente: Contra o desperdício da Experiência. São Paulo: Cortez, 2007.

SOUZA, J. O mundo desencantado. In: WEBER, M. A gênese do capitalismo moderno. Tradução de Rainer Domschke. São Paulo: Ática, 2006.

Patologias da modernidade: um diálogo entre Habermas e Weber. São Paulo: Annablume, 1997.

WIGGERSHAUS, R. A escola de Frankfurt: História, desenvolvimento teórico, significação política. Tradução de Lilyane Deroche-Gurgel e Vera de Azambuja Harvey. Rio de Janeiro: Difel, 2002.

\section{Endereço para correspondência}

Aluísio Ferreira de Lima

Universidade Federal do Ceará, Rua Anahid Andrade, 471, Praça Senador Figueira, Centro, CEP 62011-000, Sobral - CE, Brasil

Endereço eletrônico: aluisiolima@hotmail.com

Recebido em: 15/03/2010

Aceito para publicação em: 20/04/2010

Acompanhamento do processo editorial: Ariane P. Ewald e Jorge Coelho Soares

\section{Notas}

* Psicólogo com Pós-Doutorado, Doutorado e Mestrado em Psicologia Social pela Pontifícia Universidade Católica de São Paulo (PUCSP) e Especialista em Saúde Mental pela Escola de Enfermagem da Universidade de São Paulo (EEUSP). Professor Adjunto do Setor de Psicologia Social do Programa de Pós-Graduação em Psicologia, do Programa de Pós-Graduação em Saúde da Família e do Curso de Psicologia da Universidade Federal do Ceará (UFC). Bolsista de Produtividade em Pesquisa FUNCAP.

${ }^{1}$ Trabalho desenvolvido com o apoio da FUNCAP e CNPq. 